\title{
La relación entre democracia y territorio en la Constitución Política de 1991: un análisis a partir de las consultas populares en materia minero-energética ${ }^{*}$
}

\author{
Relationship between Democracy and Territory in \\ the 1991 Political Constitution: An Analysis based \\ on Mining-Energy Popular Consultations \\ A relação entre democracia e território na Constituição \\ Política de 1991: uma análise a partir de consultas \\ populares em temas mineiro-energéticos
}

\author{
Diana Carolina SÁnCHEZ-Zapata ${ }^{*}$ \\ AdRIANA MARÍA SANÍN-VÉLEZ $Z^{* * *}$ \\ Clara InÉs Atehortúa-ArRedondo ${ }^{\star \star * \star}$
}

Fecha de ReCepción: 28 de AGosto de 2020. FeCha de aprobación: 15 de noviembre de 2020

Doi: https://doi.org/10.12804/revistas.urosario.edu.co/sociojuridicos/a.9563

Para citar este artículo: Sánchez-Zapata, D. C., Sanín-Vélez, A. M., E Atehortúa-Arredondo, C. I. (2021). La relación entre democracia y territorio en la Constitución Política de 1991: un análisis a partir de las consultas populares en materia minero-energética. Revista de Estudios Socio-Jurídicos, 23(1), 99-132. https://doi.org/10.12804/revistas. urosario.edu.co/sociojuridicos/a.9563

\section{RESUMEN}

El artículo presenta, a partir del análisis de las consultas populares frente a proyectos minero-energéticos, un estudio crítico sobre las deformaciones normativas y jurisprudenciales que ha sufrido el modelo de Estado unitario, descentralizado y con autonomía

* El artículo no ha sido previamente presentado a ningún congreso, ni ha sido escrito para ponencia.

** Profesora del área de Derecho Público de la Facultad de Derecho y Ciencias Políticas, Grupo de investigación Derecho y Sociedad, Universidad de Antioquia. Correo electrónico: diana.sanchez@udea.edu.co ORCID: https://orcid.org/0000-0002-4992-8833

*** Profesora del área de Derecho Público, Grupo de investigación Gobierno y Asuntos Públicos de la Facultad de Derecho y Ciencias Políticas, Universidad de Antioquia. Correo electrónico: adriana.sanin@udea.edu.co ORCID: https://orcid.org/0000-0003-0842-6535

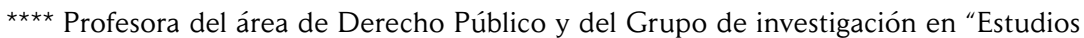
Internacionales: Derecho, Economía, Política y Relaciones Internacionales" de la Facultad de Derecho y Ciencias Políticas, Universidad de Antioquia. Correo electrónico: clara.atehortua@ udea.edu.co ORCID: https://orcid.org/0000-0002-5896-0472 
de las entidades territoriales, al igual que el debilitamiento de la participación ciudadana como pilar estructural de la forma de Estado adoptada en la Constitución Política de 1991. Se concluye que, si bien las consultas populares reabrieron importantes discusiones acerca de la relación entre democracia y territorio, las modificaciones en la materia han mostrado las limitaciones que desde el diseño constitucional ha tenido el modelo territorial colombiano. En medio de las tensiones y los debates inconclusos desde la Asamblea Nacional Constituyente sobre las relaciones entre la Nación y las entidades territoriales, los movimientos sociales están configurando la formación de una ciudadanía activa que persiste en la reivindicación de su participación en la toma de decisiones sobre su territorio como componente indispensable del fin último del Estado social de derecho y del desarrollo integral del ser humano en su contexto social propio.

Palabras clave: democracia; desarrollo participativo; Constitución Política de 1991; organización territorial; consultas populares.

\section{ABSTRACT}

The article presents a critical study of the normative and jurisprudential deformations to the model of a unitary, decentralized state with autonomous regional territories, as well as of the weakening of citizen participation as a structural pillar of the state form adopted in the Political Constitution of 1991. The study is based on the analysis of popular consultations on mining energy projects. It allows concluding that, although the popular consultations reopened important discussions about the relationship between democracy and territory, the relevant modifications have shown the limitations of the Colombian territorial model that arise from the constitutional design. Amid tensions and inconclusive debates in the National Constituent Assembly on the relationship between the Nation and territorial entities, social movements are shaping the formation of an active and qualified citizenry that persists in demanding participation in the decision-making process relating to their territory. This participation is a necessary component of the ultimate goal of the social state based on the rule of law, which is the integral development of the human being in their own social context.

Key Words: Democracy; participatory development; Political Constitution of 1991; territorial organization; popular consultations.

\section{RESUMO}

O artigo apresenta, a partir da análise de consultas populares sobre projetos de mineração e energia, um estudo crítico sobre as deformações normativas e jurisprudenciais que sofreu o modelo de Estado unitário, descentralizado e com autonomia das entidades territoriais, bem como o enfraquecimento da participação cidadã como pilar estrutural da forma de Estado adotada na Constituição Política de 1991. Conclui-se que, embora as consultas populares tenham reaberto discussões importantes sobre a relação entre democracia e território, as modificações na matéria mostraram as limitações do modelo territorial colombiano desde o desenho constitucional. Em meio às tensões e aos debates inconclusivos da Assembleia Nacional Constituinte sobre as relações entre a Nação e as entidades territoriais, os movimentos sociais vão moldando a formação de uma cidadania ativa que persiste na reivindicação por participação nas tomadas de decisão sobre seu território, como componente indispensável do objetivo último do estado social de direito e do desenvolvimento integral do ser humano em seu próprio contexto social.

Palavras-chave: democracia; desenvolvimento participativo; Constituição Política de 1991; organização territorial; consultas populares. 


\section{Introducción}

¿Son procedentes las consultas populares ( $\mathrm{CP}$ ) como un mecanismo de participación válido para que los habitantes de los municipios puedan pronunciarse sobre la realización de proyectos minero-energéticos sobre el territorio? Esta ha sido una de las preguntas en los debates constitucionales de los últimos 30 años, pues ella se refiere al reparto de competencias entre la Nación y las entidades territoriales. Si bien los principios de descentralización, autonomía y democracia participativa incorporados en el modelo de Estado adoptado en 1991 proporcionaron matices a la tradicional forma de interpretar y concebir la unidad estatal, la falta de cierre de las discusiones sobre el modelo territorial vigente desde la Asamblea Nacional Constituyente (ANC) y las remisiones legislativas al respecto han ahondado las tensiones respecto a estos asuntos constitucionales.

Este artículo tiene como objeto analizar dichas tensiones y discusiones en el marco de las CP como mecanismo de participación ciudadana en asuntos minero-energéticos, y exponer que las últimas respuestas jurisprudenciales a dichas tensiones han profundizado las promesas incumplidas por el legislativo frente al modelo territorial propuesto por la ANC en 1991. Para realizar esta lectura se toma el concepto de deformaciones normativas y jurisprudenciales, que alude al fenómeno por el cual los presupuestos del proceso constituyente frente a la forma territorial del Estado colombiano, a la participación ciudadana y a la relación entre el principio democrático y el territorio que debían ser completados por el legislador han terminado por desdibujarse por la falta de desarrollo normativo, en los casos de las omisiones legislativas, o por los desarrollos normativos y jurisprudenciales inadecuados, relativos al equilibrio necesario entre los principios organizativos del Estado. Para ello, se recurre a los hallazgos de la investigación precedente a los debates sobre las CP en el Consejo de Estado y la Corte Constitucional, en el periodo 2014-2020, en los que han participado las autoras, así como a los resultados de sus investigaciones vinculadas con la participación ciudadana, la democracia participativa, el derecho al territorio y la autonomía territorial. 
En un primer momento, se presenta el análisis de las promesas del Estado unitario, descentralizado y con autonomía de las entidades territoriales planteadas en la Constitución, donde se destacan las limitaciones del diseño constitucional que han llevado a calificar al modelo territorial colombiano como inacabado o inconcluso (Robledo, 2008, p. 178). La identificación de tales limitaciones sirve de preámbulo para exponer, en un segundo apartado, las deformaciones normativas y jurisprudenciales que han transfigurado la propuesta de organización territorial hacia la cual debía avanzar el país, en detrimento de la participación ciudadana como principio estructural del Estado. Este análisis se sirve especialmente del estudio de los pronunciamientos jurisprudenciales que hicieron nugatorio el mecanismo de las CP. Por último, se muestra que, pese a los resultados desfavorables en el escenario jurisdiccional frente a la viabilidad de las $\mathrm{CP}$, los procesos sociales que dieron lugar a ellas han consolidado movimientos ciudadanos activos que persisten en la reivindicación de la justicia ambiental y la autonomía de sus territorios.

\section{Metodología}

Se plantea una investigación sociojurídica con enfoque crítico (Duque et al., 2018, p. 21), que permitió asumir la investigación como un medio de construcción social para trazar estrategias de intervención y litigio en defensa de las CP en materia minero-energética. Los presupuestos de la investigación sociojurídica adoptada permitieron la articulación de diversos enfoques además del de los estudios críticos como la propuesta del derecho en contexto (Atehortúa-Arredondo, 2017), la investigaciónacción participativa y la estrategia de investigación cualitativa de tipo documental (Galeano, 2004).

Para mostrar un panorama general sobre las deformaciones normativas y jurisprudenciales en las discusiones sobre las CP con base en los presupuestos metodológicos, se recurrió a la lectura de los procesos sociales que han impulsado las $\mathrm{CP}$, la producción académica y los argumentos de ciudadanos y funcionarios respecto al ordenamiento territorial y a las posibilidades de las CP en tres escenarios: la ANC, la producción normativa y los procesos judiciales que discutieron las $\mathrm{CP}$, 
que culminaron en la Corte Constitucional. Dicho estudio se hizo sobre las categorías de democracia y organización territorial en el marco del diseño constitucional planteado en la Carta Política de 1991 y las tensiones suscitadas por las CP frente a la organización territorial y la participación ciudadana. En esta línea, los resultados presentados entrecruzan las diferentes fuentes utilizadas para el análisis.

\section{Resultados}

\section{Las promesas del Estado unitario, descentralizado y con autonomía de las entidades territoriales en la Constitución de 1991: las limitaciones del diseño constitucional}

Para los integrantes de la Comisión Segunda, encargados en la ANC ${ }^{1}$ del desarrollo de los temas y propuestas correspondientes al ordenamiento territorial y la autonomía regional y local, la organización territorial descansaba en cinco ideas que consolidaron la filosofía que integró el modelo propuesto y finalmente aprobado: 1) la autonomía territorial; 2) la profundización de la descentralización reconocida como un proceso iniciado desde la década del 60 del siglo Xx bajo el auspicio de las ideas de modernizar el aparato estatal; 3) el fortalecimiento económico de los entes territoriales, aspecto sin el cual no era posible hablar de una efectiva descentralización; 4) la consagración del municipio como eje fundamental del Estado, y 5) la democracia participativa (Sánchez, 2012, p. 81).

En relación con la autonomía territorial, la importancia de su constitucionalización e inclusión en la forma territorial del Estado se refleja, tal y como plantea Robledo (2010), en una afectación de las potestades del legislativo central. Esta ha sido definida por autores como Hernández (2015) como un principio que "en la práctica es meramente legal" (p. 6),

Jaime Castro, Eduardo Espinosa Faciolince, Orlando Fals Borda, Juan Fernández Renowitzky, Carlos Fernando Giraldo Ángel, Juan Gómez Martínez, Lorenzo Muelas Hurtado, Héctor Pineda Salazar, Augusto Ramírez Cardona, Carlos Holmes Trujillo, Eduardo Verano de la Rosa, Gustavo Zafra Roldán. https://enciclopedia.banrepcultural.org/index.php/ Comisi\%C3\%B3n_segunda_de_la_Asamblea_Nacional_Constituyente 
como una categoría con "un alcance bastante limitado" (Estupiñán, 2017, p. 176) y como una categoría compleja y de difícil concreción en razón a que su desarrollo no quedó plenamente configurado en la Constitución y se defirió al legislador (Robledo, 2010, p. 35). Por tanto, ha sido desde la legislación y la jurisprudencia que se han delineado los contornos específicos y los alcances para su desarrollo en atención a las diferentes materias, con base en la fórmula de "limitaciones recíprocas" (Sentencia C-123, 2014). A su vez, esta categoría adquirió dos dimensiones inescindibles: 1) como principio de la organización territorial del Estado y 2) como atributo o cualidad de las entidades territoriales (Robledo, 2010).

En el contexto constitucional colombiano, la autonomía territorial se consolidó en cuatro derechos que la convierten en el principio constitucional que orienta y determina la organización territorial del Estado y, a su vez, en el atributo que da origen a la titularidad de ciertas prerrogativas: 1) El derecho que tienen las entidades territoriales a gobernarse por autoridades propias, que presupone el direccionamiento y la gestión de sus intereses, a través de sus propios órganos de administración y gobierno; 2 ) el derecho a ejercer las competencias que les correspondan, que se encuentran principalmente en la Constitución, en el caso de los municipios -artículos 311, 313, 314, 367-, que, además, tienen por objeto desarrollar los fines y cometidos estatales, por ello se ejercen de manera coordinada y compartida o concurrente con los demás niveles territoriales (Constitución Política, artículo 288), y 3) el derecho a administrar los recursos, establecer los tributos necesarios para el cumplimiento de sus funciones y participar en las rentas nacionales.

Su carácter de principio implica que cumple al menos dos funciones dentro del ordenamiento jurídico en tanto aporta criterios de interpretación sobre la forma como deben aplicarse las demás normas y alcanza proyección normativa por la vía de la aplicación jurídica que hacen de este los jueces o por vía de la aplicación política que hace el legislador al desarrollarlo (Robledo, 2010).

La autonomía territorial se encuentra limitada por la ley, según quedó establecido en el artículo constitucional 287: "Las entidades territoriales gozan de autonomía para la gestión de sus intereses, y dentro de los límites de la Constitución y la ley". Esto quiere decir que los derechos 
antes mencionados que conforman su contenido sustantivo no son absolutos. En consecuencia, ha sido el legislador, a través de leyes ordinarias y orgánicas, la autoridad encargada de precisar el ejercicio de los derechos que reconoce la Constitución a las entidades territoriales. Esto se debe armonizar con el artículo 288 que señala que la Ley Orgánica de Ordenamiento Territorial (LOOT) establecerá la distribución de competencias entre la Nación y las entidades territoriales.

Igualmente, Pardo (2018) alude a la relación funcional que cumple el principio de descentralización con respecto a la autonomía, al señalar que los artículos 356 y 357, que regulan el sistema general de participaciones, y el artículo 366, que sintetiza las finalidades sociales del Estado, de bienestar general y mejoramiento de la calidad de vida de la población, "evidencian que, (...) las reglas de la descentralización están dispuestas en el título del régimen económico y de hacienda pública" (p. 365) con el objetivo fundamental de dar solución a las necesidades insatisfechas en salud, educación, saneamiento ambiental y agua potable mediante los planes y presupuestos de la Nación y las entidades territoriales. De esta manera, la autonomía actúa como un principio jurídico en materia de organización competencial y es además una garantía institucional necesaria para salvaguardar el carácter democrático del Estado que requiere para mantenerse vigente que al menos una porción razonable de los recursos de las entidades territoriales pueda ser administrada libremente (Sentencia C-219 de 1997).

En relación con el municipio, la propuesta que tuvo acogida final en la ANC fue aquella que reconoció que este era fundamental para la organización territorial y político-administrativa (artículo 311) como alternativa para superar la visión geográfica centralista y el esquema administrativo que imponía una relación jerárquica y vertical entre los diferentes niveles territoriales, afirmados en la Constitución de 1886. El municipio quedó considerado como la entidad del Estado con mayor proximidad al ciudadano, connotación que acogía el significado social, político y económico del concepto de comunidad local y situaba al ente local como el principal eje del desarrollo y de la acción pública.

El municipio ostenta la cláusula general de competencia para la prestación de servicios y el cumplimiento de las funciones estatales de acuerdo con los artículos constitucionales 311, 313, 314 y 367. Las demás 
entidades están instituidas para concurrir supletoria o subsidiariamente. Por estas razones, debía reconocérsele autonomía para procurarse su propio gobierno, administrar los asuntos de su competencia, poseer los recursos propios para el cumplimiento de sus funciones y el derecho a participar en las rentas nacionales (Constitución Política, artículo 287). Estas competencias y prerrogativas buscan desarrollar los fines estatales, debido a ello se ejercen de manera coordinada y compartida o concurrente con los demás niveles territoriales (Constitución Política, artículo 288).

Desde esta óptica se incorporó en el Estado el principio esencial de prelación del municipio en el aparato administrativo. El esfuerzo del Estado debía orientarse a fortalecerlo. Sumado a la importancia con que se forjó la idea de municipio en el seno de la ANC, se reconoció que no podía hacerse referencia a este como una entidad homogénea. Fue indispensable hacer un llamado a la categorización municipal (Constitución Política, artículo 320) para que la ley se ocupara de asignar competencias y recursos entre los municipios, atendiendo a sus condiciones particulares (Sánchez, 2012, p. 89).

Si bien los anteriores elementos configuran los aspectos más promisorios del modelo territorial colombiano, los estudios sobre la materia a lo largo de estos 30 años han develado sus principales dificultades y limitaciones. Entre ellas, la omisión desde el diseño constitucional de reglas precisas para garantizar la autonomía territorial, más allá de los derechos de las entidades territoriales que han sido insuficientes (Constitución Política, artículo 287) para la definición de lo que se entiende por intereses locales y competencias propias para cada uno de los niveles territoriales (Hernández, 2014; Robledo, 2008), así como la ausencia de mecanismos adecuados para gestionar los conflictos de competencias derivados de la tensión entre el principio unitario y el principio de autonomía (Robledo, 2015).

Adicionalmente, la conjunción de temas, en principio incompatibles frente a los que no hubo consenso, dio como resultado un modelo "confuso y ecléctico" (Estupiñán, 2012, p. 34), en el que los acuerdos no alcanzados se pospusieron y dejaron en manos del legislador y del mecanismo de la (LOOT), entre otros: aquellos correspondientes a la distribución de competencias entre la Nación y las entidades territoriales 
y a la asignación de las correspondientes competencias normativas (Constitución Política, artículos 151 y 288); los requisitos para la formación de departamentos y la creación de regiones, provincias y entidades territoriales indígenas (Constitución Política, artículos 297, 307, 286 y 329), al igual que otros asuntos relacionados con la planeación y el presupuesto público, comprensivos de aspectos neurálgicos para la descentralización de recursos hacia los territorios (Constitución Política, artículos 342 y 349 ).

A su vez, dos temas íntimamente conectados como la forma de Estado y la organización territorial se estudiaron separadamente por las comisiones primera y segunda de la ANC, bajo un esquema de disgregación como advierten Hernández (2015) y Robledo (2008), al paso que los temas concernientes a la hacienda pública, de los que dependía el avance en la descentralización fiscal y financiera de los entes territoriales, se desarrollaron por la Comisión Quinta. Correa y Robledo (2018) advierten sobre las consecuencias de estas contradicciones en el texto constitucional, al indicar las limitaciones del diseño institucional del Estado que se reflejan en una constitución económica centralista como expresión de un régimen presidencialista y tecnocrático que confiere, en virtud del principio de unidad, amplias facultades al gobierno, especialmente, al presidente para intervenir en la economía (p. 369).

A pesar de las promesas de la ANC, del papel del municipio y de los mecanismos de participación que buscaban esa toma de decisión local por parte de las comunidades en los asuntos de su interés, las $\mathrm{CP}$ (Constitución Política, artículo 105), mecanismos de participación clave para ello, han resultado ser un referente fáctico en el que las irregularidades del diseño institucional han permitido, lejos de las aspiraciones de la constituyente, malformaciones del Estado constitucional.

\section{Tensiones y deformaciones normativas y jurisprudenciales a la organización territorial y a la participación ciudadana}

El trabajo de la ANC, en particular el de las comisiones primera y segunda, que se concretó en la forma de Estado unitario, descentralizado y con autonomía de las entidades territoriales, tuvo en cuenta además referentes de contexto de la situación que vivía el país como 
consecuencia de la concentración de poder en los órganos centrales y de las condiciones de abandono y desatención de los territorios periféricos, circunstancias que 30 años después persisten en el territorio nacional (PNUD Colombia, 2011; Reyes-Posada, 2016).

El contexto diagnosticado hace tres décadas y percibido por la constituyente derivó en la necesidad de crear mecanismos de participación efectivos que los ciudadanos concibieran como espacios reales que les permitieran implicarse en la vida política del país (Robledo, 2010, p. 43). La Constitución de 1991 quiso dar un paso cualitativo de una democracia meramente representativa a una democracia participativa, con la consagración de los mecanismos de participación ciudadana, entre ellos, la CP (Robledo, 2014). Para producir los resultados esperados por los constituyentes, era necesario involucrar a las entidades territoriales, reconociéndoles la autonomía para gestionar sus intereses, y dotar de la eficacia requerida a los mecanismos de participación ciudadana, más aún cuando estos intereses tienen que ver con su territorio, es decir, con el espacio físico en el que pueden ejercer válidamente sus funciones y adoptar decisiones.

La idea de un ordenamiento territorial y de una organización político-administrativa para el Estado, fundamentada en la participación, no ha sido otra que la de propiciar un entorno jurídico en el que democracia y autonomía fueran inseparables (Trujillo, 2007). Desde esta perspectiva, la democracia local fue postulada como la más legítima de todas las democracias y los municipios fueron vistos como sujetos activos del desarrollo. La participación fue concebida como la fuente encargada de dotar de legitimidad la toma de decisiones sobre el desarrollo económico y social, y, con ello también, los procesos de la inversión pública (Sánchez, 2012).

La Corte Constitucional ha reconocido el carácter fundamental del principio democrático y lo ha entendido desde una dimensión expansiva, según la cual ha de procurarse su progresiva ampliación; desde una dimensión universal que significa que compromete diversos escenarios, procesos y lugares tanto públicos como privados - por ejemplo, la minería, al ser considerada una actividad de interés general y de utilidad pública-. Ello en razón a que el principio democrático se relaciona con todo lo que vitalmente pueda interesar a la persona, 
a la comunidad y al Estado, y con lo que sea susceptible de afectar la distribución, control y asignación del poder social (Sentencia C-180 de 1994; Sentencia C-150 de 2015; Sentencia T-361 de 2017).

La ANC buscó en el ordenamiento territorial, la distribución espacial del poder y los recursos el escenario propicio para la democratización de la organización estatal en Colombia (Sánchez, 2012, p. 92), pero no hubo consenso para cambiar la forma del Estado, por lo que solo puede hablarse como lo sostiene Hernández (2015) de un "proceso de descentralización en lugar de una nueva forma de Estado" (p.7).

Si bien el ordenamiento territorial quiso definirse como un elemento dinámico dentro del Estado, permeado por enfoques sociológicos sobre la relación de este con la sociedad civil, lo cierto es que la definición de la forma de Estado adoptada no puso fin a un proceso y, en cambio, a través de los temas que dejó pendientes, ha posibilitado el inicio de una etapa de reestructuración estatal en la que el papel del legislador y de la jurisprudencia constitucional han sido determinantes para la identificación de las tensiones, avances y retrocesos tanto en términos del modelo territorial, como de la fórmula de Estado social y democrático de derecho.

\section{Deformaciones normativas a la organización territorial:}

Las omisiones de la LOOT

Como resultado de la labor inconclusa frente al diseño del modelo territorial al que se hizo referencia en el primer apartado, los constituyentes dejaron en manos del legislador, en unos casos del legislador ordinario y en otros del orgánico, la definición y concreción del sistema territorial. Por tal razón se ha señalado que Colombia es un modelo unitario en formación (Robledo, 2008).

La LOOT se concretó en la Ley 1454 de 2011. Robledo (2015) afirma que el legislador orgánico hizo tres cosas: repetir disposiciones constitucionales y legales; ${ }^{2}$ establecer la cláusula residual de competencias a favor de los municipios, pero sin los recursos para ejercerlas, y, por último,

2 Por ejemplo, el artículo 29 de la Ley 1454 de 2011 reitera competencias asignadas desde la Constitución a los concejos por la Ley 388 de 1997. 
intentó "distribuir competencias entre la nación, los departamentos, los municipios y los distritos en materia de ordenación y planeación del territorio" (p. 28). Por tanto, aspectos como la asignación de competencias normativas a las entidades territoriales (Constitución Política, artículo 151); el establecimiento de los requisitos para la formación de nuevos departamentos (Constitución Política, artículo 297); el señalamiento de las condiciones para la conversión de una región en entidad territorial (Constitución Política, artículo 307); la determinación de las atribuciones, órganos de administración y recursos de las regiones, así como la de su participación en el manejo de los ingresos provenientes del Fondo Nacional de Regalías y la definición de los principios para la adopción de sus respectivos estatutos especiales (Constitución Política, artículo 307); la fijación de las condiciones para la conformación de las entidades territoriales indígenas (Constitución Política, artículo 329) para la creación de provincias como entidades territoriales (Constitución Política, artículo 286), y los requisitos para la creación de distritos no fueron regulados en la Ley 1454 de 2011. Algunos asuntos han tenido que desarrollarse en leyes orgánicas posteriores como la Ley 1962 de 2019, que estableció las condiciones para la conversión de regiones administrativas de planificación en entidades territoriales, o la Ley 1617 de 2013 para los distritos.

Otras materias, como las referentes a la creación de entidades territoriales, han merecido el señalamiento expreso de omisiones legislativas por la Corte Constitucional en la Sentencia C-489 de 2012 y pese a exhortar al legislador para que regule la materia, en la actualidad el asunto se encuentra desarrollado por el Decreto 1953 de 2014, expedido con fundamento del artículo 56 transitorio de la Constitución, que dispuso un régimen especial con el fin de poner en funcionamiento los Territorios Indígenas respecto de la administración de los sistemas propios de los pueblos indígenas hasta que el Congreso cumpla con lo dispuesto en el artículo 329 de la Constitución y atienda a la exhortación de la Corte Constitucional.

A su vez, otros aspectos no fueron propiamente omitidos, sino desarrollados en el sentido de las malformaciones que frente a las promesas constitucionales propone este artículo: es el caso de los esquemas asociativos contenidos en la LOOT, mediante los cuales se desarrolla una 
figura asociativa que se concreta mediante los llamados contratos plan, figura administrativa que nada tiene que ver con la descentralización territorial ni con las materias de las que debía ocuparse la LOOT.

Por tanto, a la idea de autonomía que implica que los territorios no se encuentren subordinados a la Nación, que supone la ausencia de competencias jerarquizadas, se le ha dado contenido desde las leyes ordinarias y la jurisprudencia. Pero como advierte Suelt-Cock (2013), el desarrollo regional se ve afectado por tres aspectos: las limitaciones de los recursos a las entidades territoriales, favoreciendo la administración central; el desarrollo jurisprudencial del principio de autonomía, privilegiando la autonomía de tipo administrativo, y que la LOOT "privilegia los esquemas asociativos sobre el desarrollo del principio y derecho de la autonomía y la descentralización" (p. 327).

Las tareas centrales de la LOOT, en cuanto a aspectos medulares de la organización territorial, continúan pendientes, y el impulso renovado que intentó dársele a la descentralización con la Constitución de 1991 no logró los objetivos esperados como consecuencia de los desarrollos normativos y jurisprudenciales. Ello ha contribuido al escalamiento de conflictos socioambientales, especialmente aquellos producidos por proyectos extractivos en los territorios (Global Witness, 2020). ${ }^{3}$ Esta situación ha estado presente en la discusión constitucional. La Corte Constitucional ha identificado en los debates suscitados en torno a las CP y en la implementación de proyectos extractivas varias tensiones constitucionales. Además de las mencionadas entre los principios de unidad y autonomía, que han estado presentes a lo largo de la vigencia de la Carta Política, ha identificado otras ligadas a los impactos de los proyectos en los territorios.

3 De acuerdo con los datos publicados en 2020 en el Atlas de Justicia Ambiental, Colombia aparece como uno de los países del mundo y el segundo en Latinoamérica con mayor cantidad de conflictos socioambientales identificados, caracterizados por las exigencias de participación de las comunidades afectadas por proyectos mineros o extractivos consideradas insatisfechos por la administración o por las autoridades competentes. En: https://ejatlas.org/ country/colombia. Expresión de ello es que según el informe de 2020 de Global Witness, Colombia es el país donde más se asesinan líderes ambientales en el mundo. 
Tensiones constitucionales de los impactos en materia minero-energética en los territorios

Uno de los puntos en el debate constitucional en torno a las CP son los impactos sociales derivados de diferentes actividades extractivas, la explotación del suelo y el subsuelo y quién asume sus costos. Al respecto, la Corte ha reconocido que "todo proyecto minero es diverso y obedece a condiciones ambientales y sociales diferentes, y por lo tanto las afectaciones socioambientales serán disímiles entre ellos" (Sentencia T-445 de 2016).

Estas afirmaciones reflejan, entre otras, las siguientes situaciones: primero, el ejecutivo nacional no tiene un panorama que le permita prever las consecuencias de dichas intervenciones que afectan directamente a los territorios. Este hecho dio pie a que se ordenara por la Corte Constitucional la realización de estudios sobre este aspecto (Sentencia T-445 de 2016). Segundo, ni las comunidades ni los municipios tienen incidencia real sobre la toma de decisiones en este tipo de proyectos por el déficit en términos de participación efectiva y coordinación administrativa (Sentencia SU-095 de 2018). Tercero, los impactos sociales, económicos y culturales de las actividades minero-energéticas aparecen mucho antes de que se lleve a cabo la actividad minera en sí: están presentes desde la delimitación de áreas, la entrega de licencias y concesiones y los trabajos de exploración (Sentencia SU-133 de 2017).

En ese contexto, la Corte Constitucional ha identificado varias tensiones constitucionales en el desarrollo de actividades minero-energéticas en los territorios, entre ellas que son los territorios los que deben afrontar los impactos sociales de las actividades de producción y explotación extractiva y expansiva (Ruiz-Ruiz \& Santana-Rivas, 2013) y responder por "la urgencia social" que suponen los cambios en la vida del territorio (Sentencia Su-133 de 2017). Dichos cambios inciden en los modos de vida; la soberanía alimentaria y al mínimo vital; la planeación de los usos del suelo de los territorios, y el escalamiento del conflicto armado.

En cuanto a los modos de vida, la Corte Constitucional ha reconocido la afectación que las actividades minero-energéticas provocan en ellos, impidiendo o limitando a los pobladores la posibilidad de trabajar con los recursos de su entorno, de los cuales ha dependido su 
subsistencia, por ejemplo, bloqueando el acceso a los sitios en donde tradicionalmente han emprendido sus labores como el barequeo y la pesca (Sentencia T-445 de 2016; Sentencia SU-133 de 2017). Los menoscabos de los modos de vida ponen en vilo la soberanía alimentaria y el mínimo vital de las poblaciones, vulneran las garantías de preservación de las comunidades, su cultura y los procesos productivos acordes sus "modos campesinos y pesqueros" (Sentencia C-123 de 2014; Sentencia T-445 de 2016).

Los proyectos extractivos deterioran los recursos, causando la pérdida de las actividades tradicionales para el sostenimiento de la población (Sentencia T-095 de 2015). En otros casos, la afectación se da por la apropiación de los proyectos minero-energéticos de las tierras usadas por las comunidades para sus actividades (Sentencia SU-133 de 2017).

Un ejemplo de estas afectaciones son el desplazamiento por desarrollo y el despojo sin desplazamiento. Estos fenómenos se presentan cuando la población queda vacante o no cuenta con los recursos para su subsistencia o vinculación a las cadenas productivas, debido a la variación de elementos esenciales para la permanencia y subsistencia de la población como los usos del suelo y el cambio de vocación económica, sin que medie la violencia directa por actores armados legales o ilegales (Sentencia T-445 de 2016; Ojeda, 2016; Ruiz-Ruiz \& SantanaRivas, 2013; Uribe-Kaffure, 2014). En este escenario, la población se ve obligada a salir sin que se tipifique un desplazamiento forzado violento (Ley 387 de 1997, artículo 1).

Otro fenómeno que puede presentarse es el que la Corte Constitucional ha nombrado como microenfermedad holandesa (Sentencia T-445 de 2016): la conversión de las actividades locales hacia la minería puede afectar sectores económicos en el territorio, especialmente el agrícola, hasta hacerlos inviables (Sentencia SU-133 de 2017; Sentencia T-445 de 2016).

En cuanto a los usos del suelo, los municipios como responsables de la planeación del territorio deben encarar la presión proveniente de la demanda de servicios públicos; del aumento de la población por la llegada de personal -flotante o permanente- para el desarrollo de los proyectos; las variaciones de las actividades para las que habitualmente estaban destinados el suelo urbano y rural; la imposibilidad de acceso a 
la tierra por los sujetos de reforma agraria y las víctimas de la violencia, y la ineficacia de las políticas del uso del agua, entre otras (Sentencia C-123 de 2014; Sentencia T-445 de 2016). Las actividades de explotación minero-energética inciden en la disponibilidad del suelo para las personas que viven en los lugares de influencia o afectados por el proyecto, desatando disputas por el uso digno y suficiente de este componente del territorio.

Además, los municipios deben afrontar el escalamiento del conflicto armado. La Corte Constitucional ha establecido que la actividad minera "tiene la potencialidad de afectar el orden público en un municipio y, por ende, las condiciones de vida y seguridad de los habitantes" (Sentencia T-445 de 2016), entre otras razones, porque los actores vinculados con el conflicto armado encuentran allí la posibilidad de generar recursos directamente a través de la explotación de recursos minero-energéticos o indirectamente, a través de fuentes ilícitas (Ruiz-Ruiz \& Santana-Rivas, 2013; Sentencia T-445 de 2016). Aunado a esto, las disputas respecto al acceso a recursos, tierras y usos del suelo han sido calificados como "una contra reforma agraria" por el aumento de acciones bélicas y del desplazamiento forzado de la población (Sentencia T-445 de 2016; Ruiz-Ruiz \& Santana-Rivas, 2013).

Sin embargo, no hay avances en el conocimiento de dichos impactos en los ámbitos locales ni sobre cómo hacerles frente. La Contraloría General de la República afirma, sobre el seguimiento a la Sentencia T-445 de 2016, que se han realizado estudios. Sin embargo, en ellos no se determina la incidencia de la actividad minera en el "capital natural (...) y la integridad de las comunidades asentadas en los territorios" (Contraloría General de la República, 2019, p. 15). Otro estudio de este mismo organismo sobre la efectividad de la licencia ambiental muestra que la escala a la cual se exige la línea base ambiental en dichos procesos no ofrece el detalle necesario para estimar las afectaciones de los componentes ambientales ni sociales. Por ello, se aumenta el riesgo de que las medidas de prevención, mitigación y compensación no correspondan a los impactos que genera el desarrollo de las actividades mineras en un territorio. Sumado a esto, se afirma el desconocimiento de las decisiones que en materia de ordenamiento territorial habían adoptado los municipios y distritos en los Planes de Ordenamiento y 
Manejo de Cuencas Hidrográficas (Contraloría General de la República, 2017, p. 39, 75).

Las deformaciones jurisprudenciales y la regresión en el modelo de Estado

De conformidad con Robledo y Correa (2018) no existen estudios que permitan explicar el recurso a la figura de las $\mathrm{CP}$ en el territorio (p. 360). No obstante, estas autoras presentan un balance de los principales factores que motivaron el uso de este mecanismo: el fortalecimiento del desarrollo normativo y jurisprudencial que las hizo posibles y el escalamiento de los conflictos socioambientales, entre otros.

Un primer aspecto que influyó fue la declaratoria de inexequibilidad del artículo 37 del Código de Minas, que establecía la prohibición a los entes municipales de excluir de manera transitoria o definitiva partes $\mathrm{o}$ la totalidad de su territorio para el ejercicio de actividades mineras. Al desaparecer la prohibición, se dio vía libre al ejercicio de las CP (Sentencia C-273 de 2016; Sentencia C-891 de 2002; Sentencia C-395 de 2012; Sentencia C-123 de 2014).

A su vez, el marco normativo ofrecido por la Ley 136 de 1994 y la Ley 1757 de 2015 y la expedición de sentencias posteriores representaron hitos importantes para el impulso que tuvieron las CP como la Sentencia C-035 de 2016, que prohibió la minería en páramos y condicionó el desarrollo de proyectos de interés nacional estratégicos, la C-389 de 2016, que establece algunas subreglas en materia de justicia ambiental para el ejercicio de actividades mineras, y la Sentencia T-445 de 2016 que expresamente avaló la realización de CP en materia minera (Sentencia T-445 de 2016; Sentencia C-035 de 2016; Sentencia C-389 de 2016).

En cuanto al escalamiento de los conflictos socioambientales, la dicotomía crecimiento económico-desarrollo y las tensiones constitucionales mencionadas han influido en este. Sobre este punto Rudas y Espitia (2013) señalan que a "pesar del importante peso que tiene la minería en términos de su contribución al PIB y a la generación de recursos tributarios, este papel preponderante no se refleja en las condiciones de desarrollo integral de las regiones" (p. 170), disputa profundizada con la reforma al régimen de regalías mediante el Acto Legislativo 05 de 2011. 
En este contexto, las CP representaron la oportunidad para activar el movimiento social. No fue casualidad que un año más tarde de la vigencia del nuevo sistema de regalías - Ley 1530 de 2012- se convocaran las primeras CP: Piedras, en Tolima, y Tauramena, en Casanare. En ambas triunfó, con más del $90 \%$ de los votos, la prohibición a seguir explotando minerales e hidrocarburos. Luego se realizaron 8 consultas más: Cabrera, Cajamarca, Cumaral, Arbeláez, Pijao, Jesús María, Sucre y Fusagasugá, para un total de 10 consultas populares realizadas entre 2013 y 2018. Todas de iniciativa ciudadana, 9 fueron realizadas antes de la Sentencia Su-095 de $2018^{4}$ y una (Fusagasugá) después de esta, el 21 de octubre de 2018. En todas se superó el umbral de votantes (un tercio del censo electoral). De acuerdo con la información suministrada por la Registraduría Nacional del Estado Civil a la Corte Constitucional, en total 73297 personas votaron las CP y en todas ellas, ganó el NO a las actividades de explotación minera o de hidrocarburos con más del 95\% de los votos (Sentencia Su-095 de 2018).

A pesar de esos precedentes, la Corte Constitucional en 2018 tomó una decisión regresiva en materia de autonomía territorial y democracia participativa: eliminó la posibilidad de realizar CP para la toma de decisiones sobre proyectos extractivos en los territorios (Sentencia SU-095 de 2018). Con ello se frenó un fuerte mecanismo de defensa de los territorios por medio de la participación ciudadana y se agravó el grado de indeterminación constitucional del modelo territorial. ${ }^{5}$

Esta SU también desconoció el marco jurisprudencial que hasta ese momento había sido desarrollado con respecto a la competencia de los municipios para participar y decidir sobre asuntos como el ordenamiento

4 La información sobre las consultas realizadas hasta el momento de la SU es allegada a la Corte por La Registraduría Nacional del Estado Civil y se encuentra relacionada en la Sentencia. Al respecto la Corte reconoce "el uso reiterado de esta herramienta por varios municipios del país" (Corte Constitucional, Sentencia su-095 de 2018).

5 El caso que da lugar a la SU es una tutela es presentada por la empresa Mansarovar contra la sentencia del Tribunal Administrativo de Meta que declara la constitucionalidad de la pregunta para la consulta popular en el Municipio de Cumaral. El problema jurídico identificado por la Corte fue "determinar si el Tribunal Administrativo del Meta vulneró los derechos fundamentales invocados por la sociedad demandante, al incurrir en alguna causal específica de procedencia de la acción de tutela contra providencia judicial" (Corte Constitucional, Sentencia Su-095 de 2018). Sin embargo, para resolver el problema jurídico planteado, la Corte no revisa su precedente en lo relativo a la tutela contra providencias judiciales, ni al cumplimiento de las causales genéricas y específicas para la presentación de la misma. 
del territorio, la reglamentación de los usos del suelo y la protección del patrimonio ecológico en detrimento de la democracia participativa y del municipio como entidad fundamental del Estado. Antes de dicha SU, la jurisprudencia constitucional había determinado un núcleo esencial de la autonomía territorial, a partir de su reconocimiento como principio de la organización del Estado y como garantía para asegurar el carácter democrático de este, lo que implicaba un ámbito de indisponibilidad de su contenido específico para los demás poderes (Sentencia C-035 de 2016; Sentencia C-273 de 2016; Sentencia C-298 de 2016; Sentencia C-389 de 2016).

La SU señala expresamente que modifica la jurisprudencia establecida en la Sentencia T-445 de 2016 sobre la posibilidad del uso de las CP en temas minero-energéticos. Sin embargo, en esta se advierte la deformación jurisprudencial en temas que se buscaba afianzar en la Constitución - autonomía territorial, descentralización, democracia participativa- (Sentencia C-891 de 2002; Sentencia C-983 de 2010; Sentencia C-395 de 2012; Sentencia C-150 de 2015; Sentencia C-035 de 2016; Sentencia C-273 de 2016; Sentencia T-445 de 2016; Sentencia su-747 de 1998). Es preciso anotar que el cambio de autoprecedente 6 en los temas señalados se realiza sin tener presentes las causales que la misma Corte dispuso para ello: que exista una diferencia jurídicamente relevante, que falte claridad en el precedente y que se considere errónea la jurisprudencia (Sentencia C-836 de 2001).

Un primer punto que desconoce la SU-095, al interpretar el artículo constitucional 332, que establece la propiedad estatal del subsuelo y los recursos naturales no renovables, es que el concepto de Estado no es equivalente al de Nación. Para la Corte, la competencia en las decisiones sobre los proyectos extractivos recae inicialmente en la Nación. De forma contradictoria, en la parte considerativa de la Sentencia Su-095 se afirma que el Estado “(...) no es un sinónimo de Nación, sino que es un

6 El autoprecedente o precedente horizontal le impone a la Corte el deber de ser consistente con sus decisiones previas, "ello deriva no sólo de elementales consideraciones de seguridad jurídica-pues las decisiones de los jueces deben ser razonablemente previsibles- sino también del respeto al principio de igualdad, puesto que no es justo que casos iguales sean resueltos de manera distinta por un mismo juez" (Corte Constitucional, Sentencia C-447 de 1997). 
concepto general que engloba todos los niveles territoriales". Al resolver, acude a la idea del interés general en el beneficio de los recursos en el sistema general de regalías y a la de la Nación como representante de ese interés general, omitiendo las competencias de los municipios en la propiedad y decisión sobre los recursos naturales.

El constituyente primario pretendía que, además de tener presente el interés general (que también implica bienestar social, cultural y ecológico), se tuviera en cuenta la participación y los intereses de las localidades. Es por ello que, en contraposición a la Constitución de 1886, la propiedad sobre los recursos del subsuelo pasó a ser del Estado y no exclusivamente de la Nación. A pesar de que la Corte advierte que se separa de la jurisprudencia de la Sentencia T-445 de 2016, al entender que la competencia sobre los proyectos extractivos recae inicialmente sobre la Nación, no señaló la separación expresa de otras sentencias, de las cuales la Sentencia T-445 era un desarrollo, como se precisa en el Auto 053 de 2017, y que reiteran la jurisprudencia constitucional en el sentido que es el Estado el propietario del subsuelo, entendiendo que este incluye a todos los colombianos y a todas las entidades territoriales (Sentencia C-506 de 1995; Sentencia C-035 de 2016; Sentencia C-273 de 2016).

En la toma de decisiones sobre los usos del suelo y la participación de la comunidad en esas decisiones, es importante señalar que para el momento de la su se encontraba vigente el artículo 33 de la Ley 136 de 1994, que establecía la obligación de realizar CP cuando con proyectos mineros o de cualquier naturaleza se amenazara con crear un cambio significativo en el uso del suelo y transformar las actividades tradicionales del municipio. Sin embargo, la existencia de esta norma, vigente en el ordenamiento jurídico, es omitida por la Corte. Posteriormente, siguiendo la línea marcada por la Sentencia su-095, se declaró la inexequibilidad de este artículo en la Sentencia C-053 de 2019.

Asimismo, la Sentencia SU-095 desconoce su precedente en materia de participación y principio democrático. Sobre la participación democrática, la Sentencia C-150 de 2015 advierte que el Estado debe no solo abstenerse de tomar medidas que impidan el libre ejercicio de la participación, sino que está obligado, incluso por instrumentos internacionales como la Convención Americana sobre Derechos Humanos 
y la Declaración de Río sobre el Medio Ambiente y el Desarrollo, ${ }^{7}$ a adoptar las medidas necesarias para evitar que autoridades o particulares interfieran en el libre ejercicio de esta. El Estado debe implementar medidas que optimicen el desarrollo de diversas formas de participación y evitar el retroceso en la protección alcanzada, lo que implica no solo la progresividad sino la no regresividad en la participación, sus mecanismos e instrumentos.

En la Sentencia SU-095 la Corte entiende en unos apartes la participación como democracia representativa, en otros la entiende como un cumplimiento de la socialización, conceptos todos que desdibujan el diseño de la Constitución de 1991. Así, al referirse a los criterios para la definición de los mecanismos de participación ciudadana, la Corte afirma que "debe tenerse en cuenta que las autoridades de las entidades territoriales, en el marco de la democracia participativa, representan a la ciudadanía y por tal razón en algunos casos la participación ciudadana puede realizarse a través de los representantes" (Sentencia su-095 de 2018). Al referirse a la información que remite la Agencia Nacional de Minería con los procedimientos para una participación efectiva del municipio en la toma de decisiones del proceso de titulación minera, advierte que hay unas etapas previas con el objetivo de "informar en forma precisa y técnica sobre las actividades mineras que se llevan a cabo en un determinado territorio". Señala que se realizan audiencias públicas con la ciudadanía con el fin de brindar información de los títulos mineros y garantizar la participación, pero que en ellas "no se adoptan decisiones, pues se trata de un espacio en el que se reciben opiniones, informaciones y documentos, que deberán tenerse en cuenta en el momento de la toma de decisiones por parte de la autoridad ambiental competente" (Sentencia Su-095 de 2018). Se circunscribe entonces la participación a escenarios limitados, donde las discusiones y propuestas de la comunidad son solo un insumo que no tiene vinculación en la toma de decisiones.

En virtud de los dispuesto por el artículo primero de la Ley 99 de 1993 “El proceso de desarrollo económico y social del país se orientará según los principios universales y del desarrollo sostenible contenidos en la Declaración de Río de Janeiro de junio de 1992 sobre Medio Ambiente y Desarrollo". Sobre este artículo la Corte Constitucional se pronunció en la sentencia C-528 de 1994 refiriéndose a su obligatoriedad y a la capacidad de producir efectos jurídicos. 
El principio democrático, base de la Constitución de 1991, implica entender la participación como una participación efectiva, tal como la ha entendido la jurisprudencia (Sentencia C-395 de 2012; Sentencia C-150 de 2015; Sentencia SU-747 de 1998). Por participación efectiva no se puede entender actos de socialización o simples actos protocolarios, tampoco es la votación por los representantes. En la jurisprudencia constitucional se ha entendido que "el Constituyente sustituyó la participación meramente retórica del ciudadano por un principio de participación efectiva, dotada de mayor fuerza vinculante en relación con las decisiones estatales y comunitarias" (Sentencia C-891 de 2002).

Las decisiones relativas al cuidado y a la protección del ambiente y de los recursos naturales no son exclusivas de la Nación, sino que les corresponden a los diferentes niveles territoriales. En desarrollo del principio de autonomía, el municipio tiene competencias para la protección del medio ambiente y de sus recursos naturales. El numeral 9 del artículo constitucional 313, establece en los concejos la tarea de dictar las normas necesarias para la defensa del patrimonio ecológico del municipio; normas que, de acuerdo con el principio de rigor subsidiario, pueden ser más rigurosas, pero no más flexibles (Ley 99 de 1993, artículo 63). La participación ciudadana se hace más necesaria cuando se afecta el derecho colectivo al ambiente y el acceso al agua y se amenaza la salud o los derechos de las generaciones futuras; la participación ciudadana en asuntos ambientales ayuda también a garantizar la justicia social ambiental (Sentencia C-389 de 2016).

Paradójicamente, la conclusión a la que llega la Sentencia Su-095, en la parte considerativa, es que hay un déficit de mecanismos de participación en la toma de decisiones sobre asuntos minero-energéticos; pese a tal consideración, esta limita el mecanismo que había sido efectivo para dicha participación (las CP). En las conclusiones sobre los mecanismos de participación, expresa: "se identifica que los mecanismos [de] participación ciudadana (...) no son suficientes para garantizar los postulados constitucionales. Ello explica la razón por las cual las comunidades se han visto avocadas a utilizar la consulta popular". Déficit que además es catalogado por la misma sentencia como "un déficit de protección constitucionalmente inadmisible". 
La Corte opta por dar una orden al legislativo para que corrija dicho déficit, pues es a este a que le corresponde regular los mecanismos de participación y las competencias territoriales, de acuerdo con lo establecido por la Constitución. Esta decisión es incomprensible, por una parte, porque se trata de una orden no vinculante. Pero por otra, por ser una orden innecesaria en la medida en que desconoce que el legislador ya había establecido, por medio de leyes estatutarias sobre mecanismos de participación, las CP como opciones reales para influir en las decisiones sobre asuntos minero-energéticos.

Las tareas pendientes que deja el constituyente primario, que no ha concretado el legislador orgánico, implican una indeterminación del diseño constitucional que se refuerza con esta SU. Al impedir las CP en temas mineros, se ve cuestionado el modelo de Estado descentralizado con autonomía de sus entidades territoriales, en el que el municipio constituye la entidad fundamental y en donde los ciudadanos pueden participar, de forma efectiva, en la toma de decisiones sobre los asuntos que los afectan.

\section{Movimientos sociales, búsquedas jurídicas y defensa del territorio}

Las luchas por la participación efectiva, la autonomía territorial y el territorio en sí mismo desencadenaron el uso de un mecanismo de derecho positivo - las CP- como una "herramienta de combate" (Wolkmer, 2002). El acceso a dicho mecanismo, entre otros factores, contribuyó al fortalecimiento de los movimientos sociales y la democracia, a pesar de lo acontecido en el escenario jurisdiccional con la Sentencia SU-095.

Ese fortalecimiento se muestra en los repertorios de acción social; el crecimiento y diversificación de los grupos sociales en la defensa de sus territorios y de la autonomía, y en la vinculación de los debates y tensiones constitucionales a la esfera pública. El robustecimiento de los movimientos sociales en varias ocasiones ha sido una respuesta a los embates que el Estado ha hecho para restarle fuerza a las CP y a las acciones de los colectivos sociales para sacarlos adelante.

En términos de repertorios sociales, las comunidades han promovido el uso de otros instrumentos jurídicos que habían estado reservados a sectores privilegiados para ser aplicados en favor de sus derechos 
(Wolkmer, 2002, p. 145). A modo de ejemplo pueden mencionarse las iniciativas de acuerdos que limitan las actividades extractivas en algunos municipios, como las experiencias de Jardín, Jericó, Támesis, Caicedo, Cañasgordas y Urrao en el departamento de Antioquia, que han tenido apoyo y promoción de la ciudadanía y de organizaciones sociales y académicas (Argumedo et al., 2019). Dicho apoyo no se ha limitado a los diálogos con los concejos, sino que ha llegado al ámbito judicial cuando se ha debatido la legalidad de dichos actos.

En sede judicial se han promovido otro tipo de acciones, como la acción de nulidad sobre actos administrativos y contratos. Tal es el caso de la propuesta para mitigar las acciones del proyecto "La Colosa" en Cajamarca, Tolima. Esta acción fue impulsada por los mismos colectivos que antes impulsaron la CP (Reunión citada por Tierra Digna, 2019). Aunado a esto se han impulsado ideas para que la ciudadanía le otorgue valor a otro tipo de actividades sobre las extractivas: "comida es lo que llena el estómago y alimento es lo que le hace bien al cuerpo" y "la minería no solo envenena el agua, sino el corazón de la gente" son algunas de las frases usadas para ilustrar las búsquedas de las poblaciones de Cajamarca y San Lorenzo, Nariño. Estas consignas han sido la base para comercializar sus productos como verdaderos "alimentos" y para que las generaciones futuras vean en la agricultura una opción cultural y económicamente sostenible (Reunión citada por Tierra Digna, 2019).

Así mismo, han hecho alianzas no tradicionales entre diversos actores. Primero, con movimientos sociales con sus mismos intereses en otros territorios - algunos de ellos no conectados geográficamente-. A partir de puntos de encuentro como el acceso a la justicia ambiental y su relación con los derechos humanos, han dado a conocer las violaciones a la autonomía territorial y las diferentes formas de defender su territorio. Un ejemplo fue el Encuentro por la Justicia Hídrica, realizado en noviembre de 2019. Allí, movimientos sociales de la Guajira, Antioquia, Boyacá, Cundinamarca y Tolima, entre otros, se reunieron para dar a conocer los impactos de las actividades extractivas en su territorio, por qué ellas representan injusticias hídricas y ambientales, y la manera en que han hecho resistencia. En este encuentro se puso de presente la incertidumbre a la que están sometidos los territorios debido a la escalada de las actividades extractivas y la necesidad de promover 
formas de resistencia territorial e incluir esa situación en la agenda de negociación promovida por el Paro Nacional del 21N (Encuentro Justicia Hídrica y Energética, 2019). Segundo, se aliaron con los receptores de la cadena productiva de alimentos, cuyo convenio más conocido es aquel entre los productores de Cajamarca y la cadena de restaurantes Crepes E Waffles, que para el 2018 implicaba la producción de entre 500 y 700 kilos semanales de Arracacha (Montaño, 2018).

Lo novedoso de estas alianzas radica en la discusión y negociación clara, directa y horizontal para lograr que las luchas sean entendidas como lo que son: búsquedas colectivas que deben ser discutidas con toda la información disponible en los diferentes escenarios públicos (Rojas-Hernández, 2018). Muestra de ello es también el proceso desarrollado por la Alianza Colombia Libre de Fracking, que agrupa más de 100 organizaciones y ha promovido diversas propuestas, entre ellas la radicación, con el apoyo de cerca de 42 congresistas de diferentes bancadas, de un proyecto de ley para prohibir esta práctica (Semana Sostenible, 2020).

Además, se ha recurrido a la utilización de los discursos en medios de comunicación. Si bien muchas de las notas de prensa han girado en torno a las $\mathrm{CP}$, en ellas se exponen las críticas a las actividades extractivas desde los territorios (González, 2019; Montaño, 2018; Semana Sostenible, 2018b). Estas notas han hecho contrapeso a las acciones de las compañías interesadas en realizar actividades extractivas. Un ejemplo de ello es lo acaecido con el proyecto Quebradona, Jericó, en el que se ha hecho un despliegue publicitario para el proyecto que ha sido controvertido por las organizaciones sociales e incluso se han hecho denuncias públicas sobre la injerencia de la empresa en entidades como los colegios (Restrepo González, 2019; Rojas-Correa, 2020).

Otra forma de comunicar ha sido la creación de personajes para la defensa del territorio. Es el caso de "Getulio Montaña Laguna y Quejulia Páramo" creados como una forma de denunciar las desigualdades territoriales extractivas en la provincia del Sugamuxi, Boyacá (Campesino sumercé, n.d.).

Los aspectos documentados muestran que las CP en Colombia han sido ante todo una estrategia de protesta de las comunidades contra los proyectos minero-energéticos, que se vieron determinadas, de acuerdo 
con Dietz (2018), por la consolidación de una estructura de oportunidad política (EOP). Si bien esa EOP cambió desde el entorno jurídico con la Sentencia SU-095, las situaciones de EOP no han implicado la desmovilización de las comunidades, que han identificado y fortalecido nuevas oportunidades normativas y políticas.

Se han establecido redes de apoyo entre organizaciones territoriales, ONG, academia y aliados políticos y se ha recurrido a las redes sociales y a las voces de personas influyentes con el fin de informar a la sociedad de lo que sucede en las diferentes comunidades y de los peligros que enfrentan. Se busca un accountability social, que como señala O'Donnell (2004), es un mecanismo por el cual se realiza un control no electoral a las autoridades desde la ciudadanía y los movimientos, que pretende dar a conocer los errores de esta, imponer una agenda pública o activar el control entre las instituciones (accountability horizontal) para lo cual emplean herramientas institucionales y no institucionales (p. 24).

Con este accountability social se busca generar reacciones de la sociedad por medio de marchas y tendencias en redes sociales, entre otras alternativas, buscando la receptividad de quienes van a tomar las decisiones sobre los proyectos extractivos en los territorios. Es una revisión de la accountability vertical (Smulovitz \& Peruzzotti, 2000) y una forma de hacer saber a los representantes que las decisiones que tomen sobre estos temas influirán en su futuro político, pues quienes habitan los territorios están atentos a las decisiones y propuestas que se realicen al respecto, que pueden significar eventualmente castigos en las urnas.

Jiménez-Jiménez (2016) mostró como esa accountability social fue eficaz en el caso del Páramo de Santurbán: se evitó la realización del proyecto Angostura en 2011. Este accountability social potenció la participación ciudadana con una estrategia mediática que llegó a un cubrimiento nacional con el posterior desistimiento de la empresa (Jiménez-Jiménez, 2016), que sigue hoy en búsqueda de evitar nuevos proyectos en la zona del bosque altoandino.

La Constitución de 1991 le apuesta a una evolución de los conceptos de democracia y territorio, busca cambiar la democracia representativa y de decisiones desde el centro, unitarias y homogéneas. Ese tipo de toma de decisiones no es la planteada en una democracia participativa, 
una democracia fuerte que como la define Barber (2004) se trata de un modelo participativo en el que se gestionan los conflictos "a través de una proceso de autogobierno participativo y cercano y de la creación de una comunidad política capaz de transformar a individuos privados dependientes en ciudadanos libres, amén de los intereses privados y parciales en bienes públicos" (p. 202). La idea del bien común se entiende de manera diferente a la de interés general, establecida en la Sentencia su-095. Así, la democracia, dice Shapiro (2005), será un sistema que pueda gestionar las relaciones de poder entre personas que no están de acuerdo con otras cosas sobre la naturaleza del bien común, pero que comparten el interés de evitar la dominación (p. 204).

Las barreras que el Estado ha puesto para las CP en temas mineros no han sido suficientes para interrumpir el trabajo de los movimientos sociales para enfrentar las actividades extractivas. De ello dan cuenta dos situaciones: la primera, la financiación con recursos propios de las CP ante la negativa de la Registraduría Nacional del Estado Civil de llevarlas a cabo - caso de los municipios de Mercaderes y San Lorenzo- (Semana Sostenible, 2018a; Semana Sostenible, 2019). La segunda, es la convocatoria a votar CP con esta finalidad, luego de que la Corte Constitucional declarara este mecanismo como no adecuado para este debate, como en el caso de Fusagasugá (Semana, 2018). Estos ejemplos dan cuenta de que la legitimidad de los procesos y mecanismos de participación están dadas por las luchas territoriales que, en ese sentido, seguirán promoviendo la defensa de sus territorios.

\section{Conclusiones}

Los debates inconclusos de la ANC con respecto a la organización territorial del Estado y las relaciones entre la Nación y las entidades territoriales han dado pie para que, a través de las omisiones legislativas o desarrollos normativos y jurisprudenciales inadecuados, se presenten deformaciones de los presupuestos constitucionales referentes a dichos asuntos. Una muestra de ello es lo acaecido con las discusiones sobre las posibilidades de las CP para la defensa de los territorios frente a las amenazas minero-energéticas. 
El constituyente de 1991 identificó un contexto, aún existente, en el que era necesario ampliar los mecanismos de participación ciudadana como alternativa para profundizar la relación entre democracia y territorio. De ahí que, a partir de la Constitución de 1991, la democracia participativa juegue un papel fundamental en el ejercicio de competencias entre la Nación y las entidades territoriales. Precisamente por ello, el análisis de las temáticas concernientes a la organización del territorio y del reparto de competencias en materia de ordenamiento territorial y de asuntos minero-energéticos no pueden sustraerse de las responsabilidades que impone al Estado el reconocimiento de sus finalidades sociales como un Estado democrático, participativo y pluralista, que debe facilitar la participación de todos los habitantes en las decisiones sobre su vida económica, política, administrativa, ambiental y cultural.

Sin embargo, en un escenario de múltiples y profundos conflictos socioambientales y tensiones constitucionales y sociales, la participación ciudadana sufre embates a consecuencia de dichas deformaciones jurisprudenciales y normativas, como ocurrió con la SU-095. En esta sentencia, la Corte Constitucional dejó sin efecto este mecanismo de participación para decisiones sobre proyectos minero-energéticos en el territorio. Dicha decisión profundizó el grado de indeterminación del modelo territorial heredado desde el diseño constitucional, no resuelto en la LOOT en cuanto al reparto de competencias y al establecimiento de reglas para el ejercicio de competencias entre la Nación y las entidades territoriales, en detrimento del municipio, la entidad territorial fundamental dentro de la estructura estatal. No obstante las limitaciones a las $\mathrm{CP}$, su uso ha fortalecido la democracia y la participación ciudadana, lo que es evidente en la movilización ciudadana que persiste en la utilización de estrategias que trascienden los mecanismos jurídicos que les han sido negados.

\section{Referencias}

Argumedo, D. E., Acosta, L. D., Arias, M., Arismendy, A., Bedoya, M. A., Correa, S., Osorio, L. G., E Torres, Y. E. (2019). Prohibición de las actividades mineras como manifestación del ejercicio de la autonomía municipal: 
¿avances o retrocesos? Diálogos de Derecho y Política, (23), 53-81. https:// revistas.udea.edu.co/index.php/derypol/article/view/339651

Atehortúa-Arredondo, C. I. (2017). Los procesos de espacialización en las ciudades: una alternativa de la intervención estatal a la superación del desplazamiento forzado. Colombia 2004-2015.

Barber, B. (2004). Democracia fuerte. Política participativa para una nueva época (tdr. Juan Jesús Mora). Almuzara.

Colombia, Congreso de la República. Acto Legislativo 05 de 2011, Por el cual se constituye el Sistema General de Regalías, se modifican los artículos 360 y 361 de la Constitución Política y se dictan otras disposiciones sobre el Régimen de Regalías y Compensaciones (18 julio 2011).

Campesino sumercé. (n.d.). Viñeta de Despojo Getulio Montaña Laguna y Quejulia Páramo. http://campesinosumerce.com/portfolio/getulio/\# G gid=1 $\mathrm{G}$ pid=9 Colombia, Congreso de la República. Ley 387 de 1997, Por la cual se adoptan medidas para la prevención del desplazamiento forzado; la atención, protección, consolidación y esta estabilización socioeconómica de los desplazados internos por la violencia en la República de Colombia (18 julio 1997).

Colombia, Congreso de la República. Ley 99 de 1993, Por la cual se crea el Ministerio del Medio Ambiente, se reordena el Sector Público encargado de la gestión y conservación del medio ambiente y los recursos naturales renovables, se organiza el Sistema Nacional Ambiental, SINA y se dictan otras disposiciones (22 diciembre 1993).

Colombia, Congreso de la República. Ley 136 de 1994, Por la cual se dictan normas tendientes a modernizar la organización y el funcionamiento de los municipios (2 junio 1994).

Colombia, Congreso de la República. Ley 1454 de 2011 Por la cual se dictan normas orgánicas sobre ordenamiento territorial y se modifican otras disposiciones (28 junio 2011).

Colombia, Congreso de la República. Ley Estatutaria 1757 de 2015, Por la cual se dictan disposiciones en materia de promoción y protección del derecho a la participación democrática (6 julio 2015).

Colombia, Congreso de la República. Ley 1530 de 2012, Por la cual se regula la organización y el funcionamiento del Sistema General de Regalías (17 mayo 2012).

Colombia, Congreso de la República. Ley 1962 de 2019, Por la cual se dictan normas orgánicas para el fortalecimiento de la región administrativa de planificación, se establecen las condiciones para su conversión en Región 
Entidad Territorial y se dictan otras disposiciones, en desarrollo de los artículos 306 y 307 de la C. P. (28 julio 2019).

Colombia, Congreso de la República. Ley 1617 de 2013, Por la cual se expide el Régimen para los Distritos Especiales (5 febrero 2013).

Colombia, Contraloría General de la República (2017). El proceso administrativo de licenciamiento ambiental en Colombia. https://www. contraloria.gov.co/atencion-al-ciudadano/denuncias-y-otras-solicitudes-

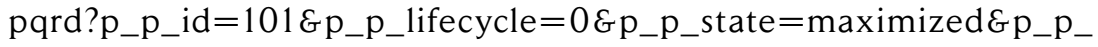
mode=viewE_101_struts_action $=\% 2$ Fasset_publisher $\% 2$ Fview_contentE_101_assetEntryld=720547E_101_type=documentEinheritRedir ect $=$ false

Colombia, Contraloría General de la República. (2019). Informe auditoría de cumplimiento. Cumplimiento de las sentencias T-622 de 2016 y T-445 de 2016 en relación con los aspectos ambientales de la actividade minera en el río Atrato. https://www.contraloria.gov.co/documents/20181/1478524/038+Infor me+Auditoria + Cumplimiento $+M A D S+$ Rio + Atrato $+a+30+$ de + junio + 2019+ls.pdf

Colombia, Corte Constitucional. Sentencia C-180 de 1994 (14 abril 1994).

Colombia, Corte Constitucional. Sentencia C-528 de 1994 (24 novimbre 1994). Colombia, Corte Constitucional. Sentencia C-219 de 1997 (24 abril 1997).

Colombia, Corte Constitucional. Sentencia C-836 de 2001 (9 agosto 2001). Colombia, Corte Constitucional. Sentencia C-891 de 2002 (22 octubre 2002). Colombia, Corte Constitucional. Sentencia C-489 de 2012 (27 junio 2012). Colombia, Corte Constitucional. Sentencia C-123 de 2014 (5 marzo 2014). Colombia, Corte Constitucional. Sentencia C-150 de 2015 (8 abril 2015). Colombia, Corte Constitucional. Sentencia T-095 de 2015 (10 marzo 2015). Colombia, Corte Constitucional. Sentencia T-445 de 2016 (19 agosto 2016). Colombia, Corte Constitucional. Sentencia C-273 de 2016 (25 mayo 2016). Colombia, Corte Constitucional. Sentencia C-035 de 2016 (8 febrero 2016). Colombia, Corte Constitucional. Sentencia C-389 de 2016 (27 julio 2016). Colombia, Corte Constitucional. Sentencia T-361 de 2017 (30 mayo 2017). Colombia, Corte Constitucional. Sentencia su-133 de 2017 (28 febrero 2017). Colombia, Corte Constitucional. Sentencia SU-095 de 2018 (octubre 11 2018). Colombia, Presidencia de la República. Decreto 1953 de 2014, por el cual se crea un régimen especial con el fin de poner en funcionamiento los Territorios Indígenas respecto de la administración de los sistemas propios de los pueblos indígenas hasta que el Congreso expida la ley de que trata el artículo 329 de la Constitución Política (7 octubre 2014). 
Correa, M., E Robledo, P. (2018). Consultas populares mineras desde el derecho constitucional: democracia, ruptura, cultura. En M. Correa, E F. Padrón (Eds.), ¿El Estado constitucional en jaque? Tomo 1: los retos del componente democrático (pp. 354-385). Universidad Externado de Colombia.

Dietz, K. 2018. Consultas populares mineras en Colombia: Condiciones de su realización y significados políticos. El caso de La Colosa. Colombia Internacional, (93), 93-117. https://dx.doi.org/10.7440/colombiaint93.2018.04

Duque, S., González, F., Cossio, N., E Martínez, S. (2018). Investigación en el saber jurídico. Editorial Universidad de Antioquia.

Estupiñán, L. (2012). El ordenamiento territorial en la Asamblea Nacional Constituyente de 1991. Lectura socio-jurídica desde el nivel intermedio de gobierno. Opinión Jurídica, 11(21), 19-37. https://revistas.udem.edu.co/ index.php/opinion/article/view/512

Estupiñán, L. (2017). El Estado unitario: La reiterada fórmula de la organización territorial en Colombia. Mutaciones y tendencias. En G. Pavani \& L. Estupiñán (Eds.), Plurinacionalismo y centralismo. Tensiones del Estado Unitario en América Latina (pp. 163-197) Universidad Libre-Ediciones Nueva Jurídica.

Galeano, M. E. (2004). Estrategias de investigación social cualitativa. El giro en la mirada. La Carreta Editores.

González, X. (20 de marzo de 2019). Comunidades votaron en 10 consultas populares mineras desde el 2013. La República. https://www.larepublica.co/especiales/minas-y-energia-marzo-2019/comunidades-votaron-en10-consultas-populares-mineras-desde-el-2013-2842036

Global Witness. (29 de julio de 2020). Defender el mañana: La crisis climática $y$ amenazas. https://www.globalwitness.org/es/defending-tomorrow-es/

Hernández, A. (2014). El ordenamiento territorial colombiano. Más allá de la Constitución de 1991. En A. Aljure; R. Araujo, E W. Zambrano (Eds.), Sociedad, Estado y derecho. Homenaje a Álvaro Tafur Galvis, Tomo II, Editorial Universidad del Rosario.

Hernández, A. (2015). Organización territorial de colombia. Doscientos años en la búsqueda de un modelo. Serie, Documentos de trabajo, Departamento de Derecho Constitucional, (57). https://icrp.uexternado.edu.co/wp-content/ uploads/sites/4/2016/05/DOC-DE-TRABAJO-57.pdf

Jimenez-Jimenez, C. (2016). El Páramo de Santurbán. Accountability social exitoso. En J. C. Henao, \& A. C. González (Eds.), Minería y desarrollo. Tomo IV. Minería y comunidades: Impactos, conflictos y participación ciudadana (pp. 465-512). Editorial Universidad Externado de Colombia. 
Montaño, E. (26 de marzo de 2018). Así está Cajamarca luego de su "no" rotundo a la mineria de oro. Semana Sostenible. https://sostenibilidad. semana.com/impacto/articulo/cajamarca-tolima-le-dice-no-a-la-mineriay-no-se-arrepiente/39755

Ojeda, D. (2016). Los paisajes del despojo: Propuestas para un análisis desde las reconfiguraciones socioespaciales. Revista Colombiana de Antropologia, 52(2), 19-43. https://doi.org/10.22380/2539472X38

O’Donnell, G. (2004). Accountability horizontal: la institucionalización legal de la desconfianza política. Revista Española de Ciencia Política, (11), 11-31. https://recyt.fecyt.es/index.php/recp/article/view/37355

Pardo Flórez, F. (2018). Los municipios y la gestión de los servicios públicos: entre la limitación de la autonomía y la obligación de garantía. En P. Robledo, H. Santaella, \& J. C Covilla (Eds.), Derecho de las entidades territoriales (pp. 353-393). Universidad Externado de Colombia.

PNUD Colombia. (2011). Informe Nacional de desarrollo Humano 2011. Colombia rural. Razones para la esperanza. Resumen ejecutivo. Autor.

Restrepo Gonzales, J. (26 de abril de 2019). Quebradona: el proyecto minero que tiene dividido a Jericó. El Mundo. https://www.elmundo.com/noticia/ Quebradonael-proyecto-minero-que-tiene-dividido-a-Jerico/376392

Reunión citada por Tierra Digna. (5 de Junio de 2019). Nota diario de campo (Entrevistador) Bogotá, Colombia.

Encuentro justicia hídrica y energética. CAJAR. (28 y 29 de noviembre de 2019). Nota diario de campo (Entrevistador).

Reyes-Posada, A. (2016). Guerreros y campesinos. Despojo y restitución de tierras en Colombia. Ariel.

Robledo-Silva, P. (2008). El panorama territorial colombiano. Revista Derecho del Estado, (21), 177-208. https://revistas.uexternado.edu.co/index.php/ derest/article/view/498

Robledo-Silva, P. (2010). La autonomía municipal en Colombia. Universidad Externado de Colombia.

Robledo-Silva, P. (2014). El papel de la democracia participativa en la creación de nuevos municipios en Colombia. En A. Montaña \& A. Ospina (Eds.), La constitucionalización del Derecho Administrativo. XV Jornadas Internacionales de Derecho Administrativo (pp. 257-278). Universidad Externado de Colombia.

Robledo-Silva, P. (2015). La ley orgánica de ordenamiento territorial: ¿una asignatura pendiente? Serie. Documento de Trabajo. Departamento de Derecho Constitucional, (31). https://icrp.uexternado.edu.co/wp-content/uploads/ sites/4/2015/05/DOC-DE-TRABAJO-31.pdf 
Rojas-Correa, T. (21 de mayo de 2020). Rector pidió datos de niños para entregarlos a compañía minera. El Tiempo. https://www.eltiempo.com/vida/ medio-ambiente/rector-pidio-datos-de-ninos-para-entregarlos-a-companiaminera-497614

Rojas-Hernandez, T. (3 de diciembre de 2018). El conflicto ambiental apenas comienza. Semana Sostenible. https://sostenibilidad.semana.com/impacto/ articulo/tauramena-historia-de-un-conflicto-ambiental-que-apenas-comien$\mathrm{za} / 42237$

Rudas, G., E Espitia, J. E. (2013). Participación del Estado y la sociedad en la renta minera. En L. Garay (Dir), Minería en Colombia. Derechos, políticas públicas y gobernanza (pp. 125-176). Contraloría General de la República.

Ruiz-Ruiz, N. Y., \& Santana-Rivas, L. D. (2013). La nueva geografía de la explotación minero-energética y la acumulación por desposesión en Colombia entre 1997 y 2012. Notas de Población, (102), 249-277.

Sánchez-Zapata, D. C. (2012). Autonomía territorial y potestad normativareglamentaria de los Concejos Municipales: hacia una redefinición del sistema de fuentes del derecho administrativo en Colombia. Universidad de Antioquia.

Shapiro, I. (2005). El Estado de la teoría democrática. Bellaterra.

Semana. (2018). Fusagasugá dice No al fracking y la minería. Revista Semana. https://www.semana.com/en-vivo-fusagasuga-sale-a-rechazar-el-frackingy-la-mineria-en-las-urnas/587730/

Semana Sostenible. (23 de noviembre de 2018a). San Lorenzo: el pueblo que sin ayuda de la Registraduría desafió al Estado colombiano saliendo a votar. Semana Sostenible. https://sostenibilidad.semana.com/impacto/ articulo/san-lorenzo-el-pueblo-que-sin-ayuda-de-la-registraduria-desafioal-estado-colombiano-saliendo-a-votar/42125

Semana Sostenible. (12 de octubre de 2018b). Los 9 municipios que le dijeron No a la minería usando la consulta popular. Semana Sostenible. https:// sostenibilidad.semana.com/medio-ambiente/articulo/los-9-municipios-quele-dijeron-no-a-la-mineria-usando-la-consulta-popular/41872

Semana Sostenible. (3 de agosto de 2019). Por el agua, habitantes de Mercaderes se rebelan. Semana Sostenible. https://sostenibilidad.semana.com/ impacto/articulo/consulta-popular-en-el-municipio-de-mercaderes/45227

Semana Sostenible. (10 agosto de 2020). No al fracking: el pedido de 36 congresistas en medio de la pandemia. Semana Sostenible. https://sostenibilidad. semana.com/actualidad/articulo/radican-proyecto-de-ley-para-evitar-elfracking-en-colombia-noticias-hoy/53967 
Smulovitz, C., \& Peruzzotti, E. (2000). Societal accountability in Latin America. Journal of Democracy, 11(4),147-158. https://doi.org/10.1353/jod.2000.0087

Suelt-Cock, V. (2013). Un nuevo paradigma del estado unitario: la asimetría territorial y los esquemas de coordinación. Vniversitas, 62(127), 309-339. https://doi.org/10.11144/Javeriana.VJ127.npeu

Trujillo, A. (2007). Democracia y territorio. El ordenamiento territorial entre el derecho y la política. Siglo del Hombre Editores - Academia Colombiana de Jurisprudencia.

Uribe-Kaffure, S. (2014). Transformaciones de tenencia y uso de la tierra en zonas del ámbito rural colombiano afectadas por el conflicto armado. Aproximación desde un estudio de caso. Revistas de Estudios Socio-Jurídicos, 16(1), 243-283. https://doi.org/10.12804/esj16.1.2014.06

Wolkmer, A. C. (2002). Sociedad civil, poder comunitario y acceso democrático a la justicia. https://www.insumisos.com/lecturasinsumisas/Sociedad $\% 20$ civil\%20y\%20poder\%20comunitario.pdf 